\title{
A study of the relation of HbA1c levels in acute coronary syndrome and its complications
}

\author{
Authors \\ Ashraf B.K. ${ }^{1}$, Jacob K Jacob* ${ }^{2}$, Jilse George ${ }^{3}$, Suma Samuel ${ }^{4}$, Bhagyanath $\mathbf{T}^{5}$ \\ ${ }^{1}$ Resident, ${ }^{2}$ Professor, ${ }^{3}$ Professor and HOD, ${ }^{4}$ Assistant Professor, ${ }^{5}$ Resident \\ Department of Medicine, Government Medical College, Ernakulam, Kerala \\ *Corresponding Author \\ Jacob K Jacob \\ Email:jacobkjacob@yahoo.com
}

\begin{abstract}
Introduction: The risk of coronary artery disease $(C A D)$ is higher in diabetic patients. In Indians, CAD occurs one decade earlier than the west. HbAlC is an easy marker of long term glucose regulation as it provides a good reflection of plasma glucose concentrations over $8-12$ weeks .Abnormal glucose metabolism is associated with increased mortality and complications following ACS. This study was conducted in ICU of Govt. Medical College, Ernakulam among patients admitted following ACS using HbAlC in blood and observing the complications for first week.

Materials and Methods: 188 patients admitted with Acute Coronary Syndrome in Government Medical college, Ernakulam between January 2016 and December 2016, were evaluated clinically and with the investigatory facilities available at this institution. Their HbAlC levels were measured at the laboratory of Government Medical college Ernakulam. The clinical features and investigation results were noted. HbAlC levels in UNSTABLE ANGINA, NSTEMI, STEMI, and in complications like arrhythmias, cardiac failure, cardiogenic shock also were studied and the data analysed.
\end{abstract}

Results and Discussion: Out of 188 patients, $63.85 \%$ were males and $36.2 \%$ females .Mean age was $61.5 \pm$ 9.5. 42. $6 \%$ had past H/O diabetes and 51.1\% had past h/o CAD. 66\% had HbAlC less than 6.5 and $11.2 \%$ had HbAlC greater than 8.5\%,22.9\% had HbAlc level between $6.5 \%$ and $8.5 \%$.Out of 188 patients, $63.3 \%$ had NSTEMI , 24.5\% had STEMI and 12.2\% had UNSTABLE ANGINA. Cardiac failure as a complication in $48 \mathrm{hrs}$, showed an increase as 17.7\%,53.5\%,66.7\% withincrease in HbAlC levels, <6.5,6.5-8.5, >8.5 respectively. Cardiac failureas a complication after 3-7 days also showed an increase as $16.1 \%, 353.5 \%$ $61.9 \% \%$ with increase in HbAlClevels, $<6.5,6.5-8.5,>8.5$ respectively.

Conclusions: Acute coronary syndrome patients admitted in ICU of Government medical college Ernakulam had optimum long term glycemic control(HbAlC $<6.5)$ in $66 \%$ of patients. NSTEMI is the most common acute cardiac state among ACS in this study which however not increased with increasing levels of HbAlc .Complications like cardiac failure in first $48 \mathrm{hrs}$ and within 1 week was significantly higher in patients with higher $\mathrm{HbAlC}$.

Keywords: Glycosylated haemoglobin, Acute coronary syndrome, STEMI, NSTEMI, Unstable angina, cardiac complications. 


\section{Introduction}

Diabetes mellitus has become the mostcommon non communicable, life style associated disease world-wide. Diabetes mellitus is associated with an increased risk of micro and macro vascular complications and an approximate two-fold greater risk of mortality compared with the general population. ${ }^{(1)}$ Complex interaction of genetics and environmental factors causes several types of diabetes. Broadly there are two types type 1 and type 2 . Type 1 is due to near total or complete absence of insulin. Type2 DM is characterized by decreased insulin secretion, insulin resistance, and increased glucose production. Type2 DM prevalence is increasing rapidly because of increasing obesity and inactivity. Diabetes is defined by the level of glycaemia above which diabetic specific complication occurs. Stress hyperglycaemia commonly occurs secondary to increased catecholamine levels. $^{(2)}$

Cardiovascular disease is now the commonest cause of death in the world. Hyperglycemia accelerates atherogenesis by the formation of glycated proteins and advanced glycation end products (AGE) which increases endothelial dysfunction. $^{(3)}$ HbA1C level>6.5 definitely diagnoses Diabetes and could be considered as a good marker of glycated proteins. Higher HbA1c levels and increased cardio vascular morbidity occurs even before diagnosis of clinical diabetes. $^{(4)}$

Thus, glycosylated haemoglobin (HbA1c) values may reveal diabetes in cases of AMI. So glycosylated hemoglobin $\mathrm{A} 1 \mathrm{C}\left(\mathrm{HbA}_{1 \mathrm{c}}\right)$ is a better marker of sugar control as it provides a good reflection of plasma glucose concentrations over 8 -12 weeks.

NICE guidelines recommend to offer all patients with hyperglycemia after ACS and without diabetes, to test for $\mathrm{HbA} 1 \mathrm{c}$ level before discharge. ${ }^{(5)}$ A significant proportion of ACS patients have diabetes, which may be undetected by current NICE criteria. Universal HbA1c testing offers utility as a simple and effective screening test for diabetes in the ACS population ${ }^{(6)}$.
Coronary atherosclerotic vascular disease is the major cause of mortality and morbidity in patients with type 2 DM. Mechanic features unique to DM are vascular effects of hyperglycemia ${ }^{(7)}$. In population-based studies, including diabetic and nondiabetic cohorts, $\mathrm{HbA} 1 \mathrm{c}$ has been reported as an independent predictor of all-cause and cardiovascular disease mortality ${ }^{(8)}$.

Quality of diabetes care is sub-optimal (HbA1c $>8 \%$ ) amongst $42-50$ per cent of diabetes patients. ${ }^{(9)}$ In patients with AMI, elevated glucose and $\mathrm{HbA} 1 \mathrm{c}$ levels on admission are associated with higher ischemic scores and increased mortality rates compared with patients with normal levels on admission ${ }^{(10)}$. HbA1c $>6.5$ in patients of ACS is associated with more complication rate ,high mortality and angiographically more severe disease. ${ }^{(1)} \mathrm{HbA} 1 \mathrm{c}$ estimation at the time of admission to ICU clearly and quickly differentiates MI patients stress induced hyperglycemia from diabetics ${ }^{(12)}$. In population-based studies including diabetic and non-diabetic cohorts, HbA1c has been reported as an independent predictor of all-cause and cardiovascular disease mortality. ${ }^{(13)}$

Prevalence of coronary artery disease in Kerala is $7.5 \%$ in rural and $11 \%$ in urban areas in previous studies. Prevalence of CAD was $21.4 \%$ in diabetic south Indian subjects. ${ }^{(14)}$

There is no study regarding $\mathrm{HbA}_{1 \mathrm{c}}$ levels and ACS in Kerala. Government Medical College, ERNAKULAM is an institution which gets drainage of patients from both rural and urban areas of Ernakulam. No data is available regarding the status of diabetic control and its impact on ACS complications.

This study intends to find the relation of $\mathrm{HbA} 1 \mathrm{c}$ levels in acute coronary syndrome and to find the proportion of high $\mathrm{HbA1c}$ with ACS and its relation with complications of ACS.

\section{Aim of the Study}

To study the relation of HbA1c levels in acute coronary syndrome and its complications 


\section{Materials and Methods}

This is a Cross sectional study conducted at the Intensive care unit, Department of medicine, Government Medical College, Ernakulam, Kerala from January 2016 to December 2016. All acute coronary syndrome patients admitted in ICU between age 30 to 70 years were included in the study.

\section{Exclusion criteria}

1)Known cases of congenital heart diseases

2)Rheumatic Heart diseases

3)Haemoglobinopathies

4)Hemolyticanemia

5) Sepsis

Sample Size was calculated as 188 samples.

\section{Sampling technique :}

All patients who get admitted in ICU with features of acute coronary syndrome satisfying the inclusion and exclusion criteria were included consecutively till the required sample size was achieved

\section{Procedure in Detail}

Proposed study was conducted over a period of one year in Govt. Medical College, Ernakulum. All patients admitted with ACS which refers to STEMI, NSTEMI and unstable angina in ICU who fulfilled the inclusion criteria were recruited to the study with informed consent. Relevant history and clinical details were obtained from each patient, as per proforma.

\section{Patient Recruitment}

Once the patient was admitted, history was taken and data collected in pre-structured proforma. Details of history, examinations and laboratory and technical investigations reports were noted from time to time. Patients were treated specifically and symptomatically.

HbA1c testing was done by immuno assay method.

Patients were stratified according to $\mathrm{HbA}_{1 \mathrm{c}}$ levels

1) $\mathrm{HbA}_{1 \mathrm{c}}$ levels less than 6.5 2) $\mathrm{HbA}_{1 \mathrm{c}}$ level 6.5

to 8.53$) \quad \mathrm{HbA}_{1 \mathrm{c}}$ level more than 8.5 and 1) the relation between different $\mathrm{HbA}_{1 \mathrm{c}}$ levels and spectrum of ACS (unstable angina, NSTEMI,
STEMI) studied and 2) the relation between $\mathrm{HbA}_{1 \mathrm{c}}$ levels and complications in first week such as arrhythmias, cardiac failure and cardiogenic shock were also studied.

\section{Data Analysis}

The data were numerically coded and entered in Microsoft Excel spread sheet. The analysis was done using the software SPSS (Statistical package for social sciences) to find out the relation between $\mathrm{HbA}_{1 \mathrm{c}}$ levels and ACS. Chi-square test has been used to find the significance of study parameters on categorical scale between two or more groups.

\section{Results}

Total 188 patients were enrolled for the study. Majority of the patients $(64.9 \%)$ belonged to the age group 61-70. The mean age of the study population was 61.5.(Table 1)Males comprised $64 \%$ of the study population and the rest were females.(Graph 1) History of CAD was observed in $51 \%$ of the patients and history of Diabetes Mellitus was seen in $42 \%$ of the patients.

Optimum glycemic levels were observed in the majority of patients. The mean $\mathrm{HbA1c}$ levels were 6.7. HbA1c levels $<6.5$ were noted in $66 \%$ of the patients. $23 \%$ had $\mathrm{HbA} 1 \mathrm{c}$ between 6.5 and 8.5 and $11 \%$ patients had HbA1c >8.5. (Table 2) HbA1c levels were compared with various types of ACS. But there was no significant association. (Graph3, Table5)

Out of the total study population $12 \%, 63 \%$ and $24.5 \%$ patients had Unstable angina, NSTEMI and STEMI respectively. Cardiac failure was the most common complication observed in 48 hours of presentation and during 3-7 days (Table 3,4). There was no significant association between types of ACS and HbA1c levels. (Table 5)

As the HbA1c levels increased there was a statistically significant increase in cardiac failure as a complication and was seen at 48 hours of admission and 3-7 days of hospital stay. (Table 6, $7,8,9)$ 
Graph 1: Percentage distribution of the sample according to sex

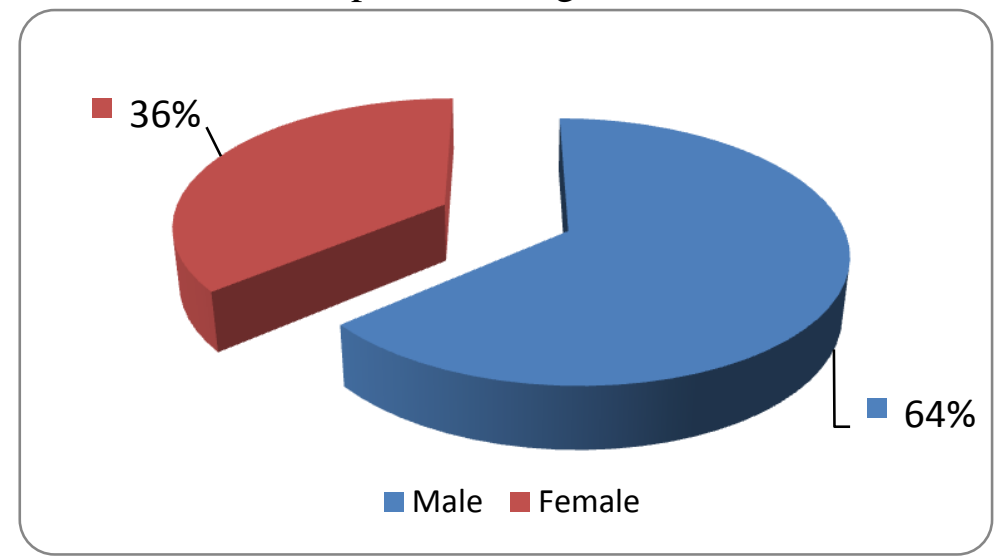

Graph 2: Percentage distribution of the sample according to $\mathrm{HbA} 1 \mathrm{C}$

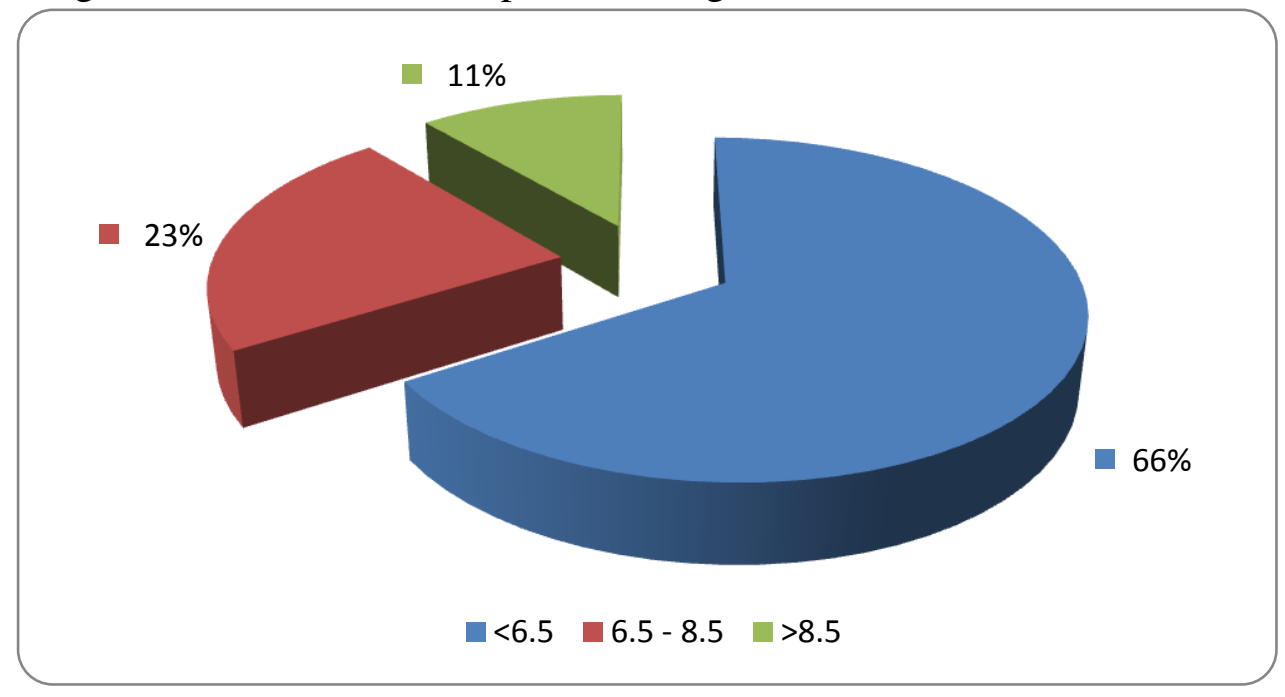

Graph 3: Comparison of ACS based on HbA1C

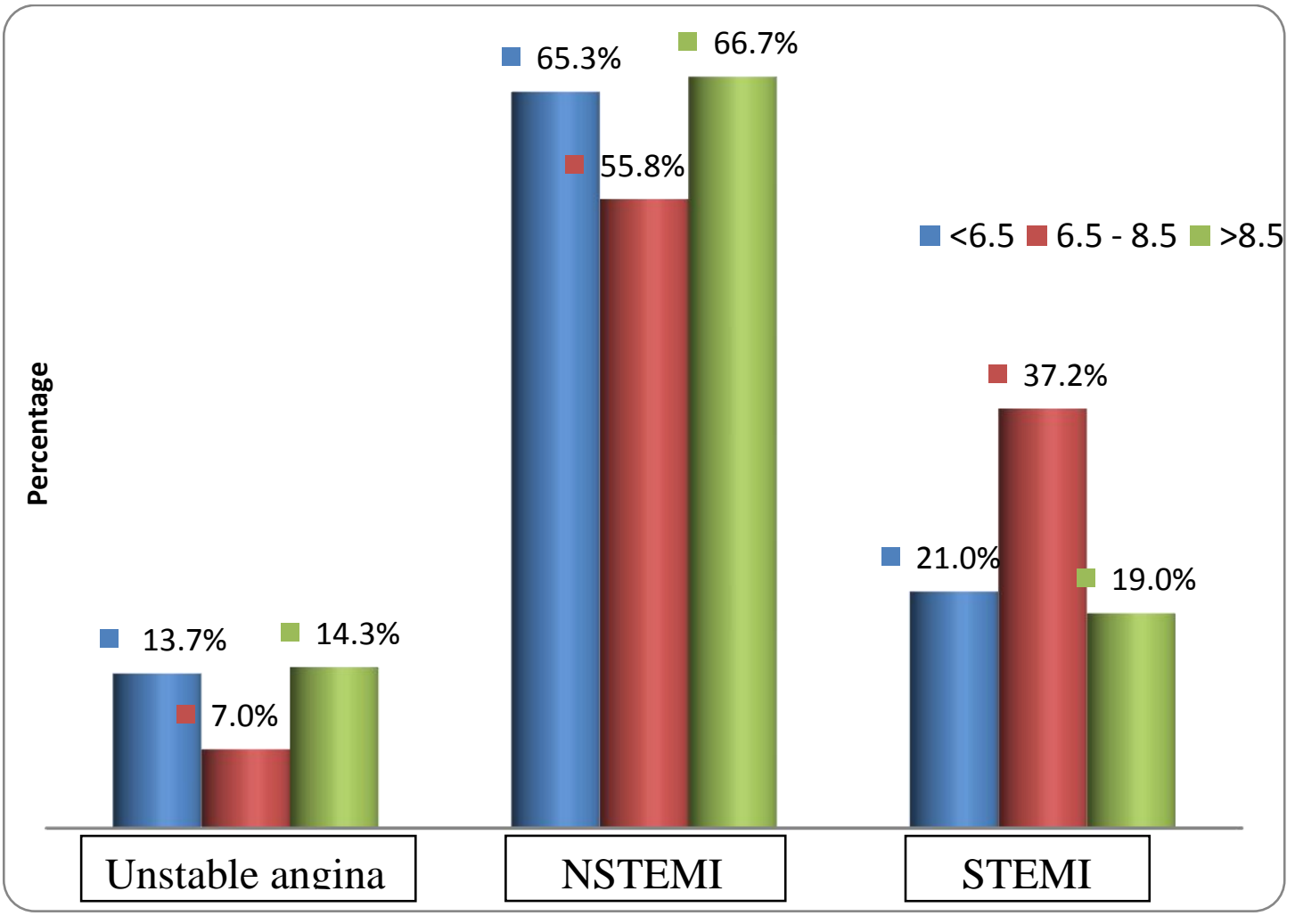


Table 1: Percentage distribution of the sample according to age

\begin{tabular}{|l|c|c|}
\hline Age & Count & Percent \\
\hline $31-40$ & 11 & 5.9 \\
\hline $41-50$ & 18 & 9.6 \\
\hline $51-60$ & 37 & 19.7 \\
\hline $61-70$ & 122 & 64.9 \\
\hline Mean \pm SD & \multicolumn{2}{|c|}{$61.5 \pm 9.5$} \\
\hline
\end{tabular}

Table 2: Percentage distribution of the sample according to $\mathrm{HbA} 1 \mathrm{C}$

\begin{tabular}{|l|c|c|}
\hline HbA1C & Count & Percent \\
\hline$<6.5$ & 124 & 66.0 \\
\hline $6.5-8.5$ & 43 & 22.9 \\
\hline$>8.5$ & 21 & 11.2 \\
\hline Mean \pm SD & \multicolumn{2}{|c|}{$6.7 \pm 1.7$} \\
\hline
\end{tabular}

Table 3: Percentage distribution of the sample according to complication in 48 hours

\begin{tabular}{|l|c|c|}
\hline Complication_48 hrs & Count & Percent \\
\hline Nil & 115 & 61.2 \\
\hline Arrhythmia & 7 & 3.7 \\
\hline Cardiac failure & 59 & 31.4 \\
\hline Cardiogenic shock & 3 & 1.6 \\
\hline Death & 4 & 2.1 \\
\hline
\end{tabular}

Cardiac failure was the most common complication observed in 48 hours of presentation and during 3-7 days.

Table 4: Percentage distribution of the sample according to Complication in 3-7 days

\begin{tabular}{|l|c|c|}
\hline Complication_3-7 days & Count & Percent \\
\hline Nil & 118 & 62.8 \\
\hline Arrhythmia & 3 & 1.6 \\
\hline Cardiac failure & 56 & 29.8 \\
\hline Cardiogenic shock & 6 & 3.2 \\
\hline Death & 5 & 2.7 \\
\hline
\end{tabular}

Table 5: Comparison of ACS based on HbA1C

\begin{tabular}{|c|c|c|c|c|c|c|c|c|}
\hline \multirow{2}{*}{ ACS } & \multicolumn{2}{|l|}{$<6.5$} & \multicolumn{2}{|c|}{$6.5-8.5$} & \multicolumn{2}{|l|}{$>8.5$} & \multirow{2}{*}{$\chi^{2}$} & \multirow[b]{2}{*}{$\mathbf{p}$} \\
\hline & Count & Percent & Count & Percent & Count & Percent & & \\
\hline Unstable angina & 17 & 13.7 & 3 & 7.0 & 3 & 14.3 & \multirow{3}{*}{5.49} & \multirow{3}{*}{0.241} \\
\hline NSTEMI & 81 & 65.3 & 24 & 55.8 & 14 & 66.7 & & \\
\hline STEMI & 26 & 21.0 & 16 & 37.2 & 4 & 19.0 & & \\
\hline
\end{tabular}

Relation of HbA1c levels with the complications of acute coronary syndrome

Table 6: Distribution of complication in $48 \mathrm{hrs}$ based on $\mathrm{HbA1C}$

\begin{tabular}{|l|c|c|c|c|c|c|}
\hline \multirow{2}{*}{ Complication in 48 hrs } & \multicolumn{2}{|c|}{$<\mathbf{6}$} & \multicolumn{2}{c|}{$\mathbf{6 . 5} \mathbf{- 8 . 5}$} & \multicolumn{2}{c|}{$>\mathbf{8 . 5}$} \\
\cline { 2 - 7 } & Count & Percent & Count & Percent & Count & Percent \\
\hline Nil & 95 & 76.6 & 14 & 32.6 & 6 & 28.6 \\
\hline Arrhythmia & 3 & 2.4 & 4 & 9.3 & 0 & 0.0 \\
\hline Cardiac failure & 22 & 17.7 & 23 & 53.5 & 14 & 66.7 \\
\hline Cardiogenic shock & 3 & 2.4 & 0 & 0.0 & 0 & 0.0 \\
\hline Death & 1 & 0.8 & 2 & 4.7 & 1 & 4.8 \\
\hline
\end{tabular}


Table 7 :Comparison of complication in $48 \mathrm{hrs}$ based on $\mathrm{HbA1C}$

\begin{tabular}{|c|c|c|c|c|c|c|c|c|}
\hline \multirow{2}{*}{$\begin{array}{l}\text { Complication } \\
\text { in } 48 \mathrm{hrs}\end{array}$} & \multicolumn{2}{|l|}{$<6.5$} & \multicolumn{2}{|c|}{$6.5-8.5$} & \multicolumn{2}{|l|}{$>8.5$} & \multirow[b]{2}{*}{$\chi^{2}$} & \multirow[b]{2}{*}{$\mathbf{p}$} \\
\hline & Count & Percent & Count & Percent & Count & Percent & & \\
\hline Nil & 95 & 76.6 & 14 & 32.6 & 6 & 28.6 & \multirow{3}{*}{$39.8 * *$} & \multirow{3}{*}{0.000} \\
\hline Cardiac failure & 22 & 17.7 & 23 & 53.5 & 14 & 66.7 & & \\
\hline Others & 7 & 5.6 & 6 & 14.0 & 1 & 4.8 & & \\
\hline
\end{tabular}

**: - Significant at 0.01 level

Table 8 : Distribution of complication in 3-7 days based on HbA1C

\begin{tabular}{|l|c|c|c|c|c|c|}
\hline \multirow{2}{*}{$\begin{array}{l}\text { Complication in 3-7 } \\
\text { days }\end{array}$} & \multicolumn{2}{|c|}{$<\mathbf{6 . 5}$} & \multicolumn{2}{c|}{$\mathbf{6 . 5} \mathbf{- 8 . 5}$} & \multicolumn{2}{c|}{$>\mathbf{8 . 5}$} \\
\cline { 2 - 7 } & Count & Percent & Count & Percent & Count & Percent \\
\hline Nil & 96 & 77.4 & 16 & 37.2 & 6 & 28.6 \\
\hline Arrhythmia & 1 & 0.8 & 2 & 4.7 & 0 & 0.0 \\
\hline Cardiac failure & 20 & 16.1 & 23 & 53.5 & 13 & 61.9 \\
\hline Cardiogenic shock & 5 & 4.0 & 0 & 0.0 & 1 & 4.8 \\
\hline Death & 2 & 1.6 & 2 & 4.7 & 1 & 4.8 \\
\hline
\end{tabular}

Table 9 : Comparison of complication in 3-7 days based on HbA1C

\begin{tabular}{|c|c|c|c|c|c|c|c|c|}
\hline \multirow{2}{*}{$\begin{array}{l}\text { Complication in } \\
\text { 3-7 days }\end{array}$} & \multicolumn{2}{|c|}{$<6.5$} & \multicolumn{2}{|c|}{$6.5-8.5$} & \multicolumn{2}{|c|}{$>8.5$} & \multirow{2}{*}{$\chi^{2}$} & \multirow{2}{*}{$\mathrm{p}$} \\
\hline & Count & Percent & Count & Percent & Count & Percent & & \\
\hline Nil & 96 & 77.4 & 16 & 37.2 & 6 & 28.6 & \multirow{3}{*}{$\begin{array}{c}36.26 * \\
*\end{array}$} & \multirow{3}{*}{0.000} \\
\hline Cardiac failure & 20 & 16.1 & 23 & 53.5 & 13 & 61.9 & & \\
\hline Others & 8 & 6.5 & 4 & 9.3 & 2 & 9.5 & & \\
\hline
\end{tabular}

**: - Significant at 0.01 level

\section{Discussion}

The present study was based on analysis of acute coronary syndrome patients admitted in intensive coronary care unit of government medical college Ernakulam under department of general medicine during the study period of twelve months, the prime aim of the study was to study the relation of HbA1c levels in ACS and its cardiac complications.

A pilot study was conducted prior to the this study to find out the number of cases of acute coronary syndrome patients admitted per year and was found to be 300 per year with an average of 25 cases per year. According to previous study by Viswanathan Mohan et al- prevalence of CAD was $21.4 \%$ in south Indian subjects ${ }^{(15)}$ Based on this sample size was calculated as 187.188 cases of cases between the ages 30 and 70 without the history of any congenital heart disease, Rheumatic heart disease, Haemolytic anemias, Haemoglobinopahies and sepsis were evaluated clinically.

All the subjects included in the study were evaluated with history, clinical examination ECG, HbA1 C levels in blood, CKMB, Trop I. 63.8\% were males and $36.2 \%$ were females. Previous h/o coronary artery disease was present in $51.1 \%$ and $\mathrm{h} / \mathrm{o}$ diabetes in $42.6 \%$. CKMB and TROP I elevation was $87.8 \%$ and $88.3 \%$ respectively. 124 patients out of $188(66 \%)$ had HbA1c level below 6.5 indicating optimum glycemic control. $43 \%$ had Hba1c levels between 6.5-8.5(22.9\%).21 patients (11.2\%) had HbA1c levels >8.5.

63.3\%(119/189) had NSTEMI 46/189 and23/189 had STEMI and Unstable angina respectively. Cardiac failure was the most common comolication in 48 hours and within first week also $31.4 \%$ and $29.8 \%$ respectively.

In comparison of ACS based on $\mathrm{HbA} 1 \mathrm{C}$, NSTEMI showed an increase From55.8\% at levels 6.5-8.5 and $66.7 \%$ at>8.5 levels with $p$ value 0.241 .

Cardiac failure as a complication in 48 hours showed increase at HbA1c levels <6.5,6.5$8.5,>8.5$ from $17.7 \%, 53.5 \%$ to66.7\% respectively, significant at $\mathrm{p}$ value 0.01 level. Cardiac failure also increased in first week at HbA1c levels <6.5, 6.5-8.5,>8.5 from $16.1 \% 53.5 \%, \quad 61.9 \%$ respectively, significant at $\mathrm{p}$ value 0.01 level.

Dubey et al found Complications was present in $25 \%$ of patients the most common being left ventricular dysfunction. ${ }^{(16)}$ 
Vinitha et al also found Severity and complications of heart disease were significantly higher in diabetics and showed a significant correlation with HbA1c. ${ }^{(17)}$

Similar study by Sheetal et al mentioned thatHbA1C> 6.5 in patients of acute coronary syndrome is associated with more complication rate, high mortality as well as angiographically more severe disease. ${ }^{(11)}$ Recent study by Ramesh naidu et al also found that patient with HbA1c $<6.5$ percent 16 out of 56 developed complication like left ventricular failure, cardiogenic shock, arrhythmias as compared to 16 of 20 patients with HbA1c >8.5 \% which was statistically significant. ${ }^{(18)}$ Left ventricular failure was most common complication followed by cardiogenic shock and Arrhythmia in patient having ACS in this study.

In our study we also found cardiac failure as the most common complication followed by cardiogenic shock in HbA1c levels above $>8.5 \%$ and positive correlation between HbA1c levels and complications like cardiac failure.

\section{Conclusions}

Acute coronary syndrome patients admitted in ICU of Government medical college Ernakulam had optimum long term glycemic control $(\mathrm{HbA} 1 \mathrm{C}<6.5)$ in $66 \%$ of patients. NSTEMI is the most common acute cardiac state among ACS in this study which however not increased in increasing levels of $\mathrm{HbA1c}$.Complications like cardiac failure in first 48 hrs and within 1 week was significantly higher in patients with higher HbA1C.

\section{Limitations of the Study}

- The study period was one year only.

- Being a Tertiary care centre in metro city, study may not always represent actual situation in the community.

Conflicts of interest: Nil
Bibliography

1. Mulnier HE, Seaman HE, Raleigh VS, Soedamah, Muthu SS. Mortality in people with type 2 diabetes in the UK. Diabet Med 2006;23:516-521.

2. Husband DJ, Alberti KG, Stress hyperglycaemia during acute Myocardial infarction: An indicator of pre-existing diabetes? Lancet, 1983; 2: 179-81

3. Brownlee M. Advanced glysosylation in diabetes and aging. Ann Rev Med 1988; 46: 223-4.

4. Haffner SM, Lehto S, Ronnemaa T, Pyorala K. Mortality from coronary heart disease in subjects with type 2 diabetes and in non diabetic subjects with and without prior myocardial infarction. N Engl J Med 1998;339:229-34.

5. HYPERGLYCEMIA IN ACS Management; NICE Guidelines.; nice.org.uk/guidance/cq130

6. McCune C, Maynard S, McClements B Lindsay $\mathrm{HbA1c}$ for Diabetes Screening in Acute Coronary Syndrome:time for a reappraisal of the guidelines? Ulster Med J 2015;84(3):154-156

7. MEDICINE UPDATE 2010; Vol 20

8. Kishore P, Kim SH, Crandall JP. Glycemic control and cardiovascular disease: what's a doctor to do? Curr Diab Rep 2012; 12: 255-264 [PMID: 22467273 DOI: 10.1007/s11892-012-0268-5]

9. Mohammed K. Ali, K.M. Venkat Narayan\& Nikhil Tandon Diabetes \& coronary heart disease: Current perspectives Indian J MedRes 132, November 2010, pp 584-597.

10. Mahmut Cakmak MD, Nazmiye Cakmak MD, Sebnem Cetemen MD The value of admission glycosylated hemoglobin level in patients with acute myocardial infarction Can J Cardiol 2008;24(5):375378.

11. Sheetal D Vora,et al A Study of Glycosylated Hemoglobinin acute 
coronarysyndrome. National journal of community medicine vol 7 issue 2 feb 2016

12. Nayak Rashmi and Chauhan Vinay Singh. Glycosylated Haemoglobin as adiagnostic marker of diabetes mellitus in acute myocardial infarction and correlation with diaterypattern, international research journal of medical sciences vol3(6)1-4 june2015

13. Chiara Lazzeri, Serafina Valente, Marco ChiostriClinical significance of glycated hemoglobin in the acute phase of ST elevation myocardial infarctionWorld $\mathbf{J}$ Cardiol2014 April 26; 6(4): 140-147

14. Viswanathan Mohan et al"'epidemiology of cardiovascular disease in type 2diabetes :theindian Scenario \{"journal of Diabetes Science and Technology' 'vol 4 issuel jan 2010 \}

15. Amitani M Sultanqaboos University Med J.Aug 201 3vol 13ISS 3 ,PP 368-370 E Pub25 Jun 13 Sub 21 May 13,

16. T. N. Dubey, Kaustubh Mundada, A Arya. Correlation of HbA1c with mortality and severity in acute coronary syndrome. International Journal of Contemporary Medical Research 2016;3(8):2244-2247.

17. Vinita Elizabeth Mani*, Mary John**, Rajneesh Calton Impact of HbAlc on Acute Cardiac States JAPI • JUNE 2011 • VOL. 59

18. Y. Ramesh Naidu, Y. Sharmila, Y.Nischal, V. Srinivas, V. Satyaprasad. "Study of HbA1c levels in Acute Coronary Syndrome". Journal of Evolution of Medical and Dental Sciences 2015; Vol. 4, Issue 77, September 24; Page: 1327413278, DOI: 10.14260/jemds/2015/1909 